\title{
Examining Effect of Organizational Structure Dimensions on the Knowledge management (Case Study: Payame Noor Universities of Semnan Province)
}

\author{
Alireza Mikaeili ${ }^{1}$, Alireza Ghorbani ${ }^{2}$, Vahid Babaei Agha Maleki - Poyan Ali ${ }^{2}$, Abbas \\ Zadeh $^{3}$, Mahmood Omrani ${ }^{4}$
}

\begin{abstract}
Transferring and understanding high volume of information and knowledge in organizations are affective internal and external factors. One of the effective internal factors on the knowledge management in organizational activities are divided, organized and coordinated. Organizations have created structures to coordinate factors of doing task and to control acts of members. In this research, structural Equation Method (SEM) is used for examining whether organizational structure dimensions have positive effect on knowledge management in Payame Noor organization in Lorestan province or not. Results of the research showed that there is direct and significant relationship between complexity dimension and knowledge management, formality dimension and knowledge management and centralization dimension and knowledge management. This means that the more complexity, formality and centralization dimensions, the more knowledge management effect in the organization.
\end{abstract}

Keywords: centralization, formality, knowledge - management, complexity.

\section{Introduction}

Organizational structure is the way or method by which organizational activities are divided, organized and coordinated. Organizations have created structures to coordinate activities of doing task and to control acts of members. Organizational structure is visible in organizational chart. Organizational chart is also a visible symbol of total activities and procedures of the organization. Many variables are named as organizational structures dimensions including administrative components, independence, centralization, and complexity, delegation of authority, separation, area, specialization, standardization, and vertical hierarchy levels. Among these factors, most scholars have consensus on three-dimensions of complexity, formality and believed that it includes the organizational structure. In today complex world, organizational knowledge is quickly converted into the main competitive advantage of the organizations, organizational knowledge in the surging contemporary world is the appropriate opportunity for organizations knowing it well and manage it and also, is serious threat for organizations that less focused on environmental changes and not knowing it. In this regard, knowledge management is a methodology for producing, maintaining and using all facilities of huge collection of knowledge that each organization has used in its daily activity. Study

Author's Address

1 Department of Managemant, Semnan university.

2 Islamic Azad university, branch of Firooz kooh). about organizations is considered as the most effective organization in the economic, social and cultural change of countries in order to keep up with global criteria and indicators of organizational improvement along achieving the long-term objectives in recent years and many researchers are carried out. Some researchers

(Demir \& Kocabas, 2010; Tohidi, Jafari \& Afshari, 2010) have studied conceptual structure, some have studied effective factors on forming organizations (kushinta, Zaikin, Rozewski \& Malachowski, 2009; Guven 2005), and some have studied explanation of its effects (Ozmen 2010; Kesim 2012). Given that organizational knowledge is central building in the structure of organizations, focus on its dimensions and role is of importance (Chen \& Huang 2007). This growing importance in study of organizations and knowledge is somewhat resulted from findings indicating structural knowledge is the most important source of improvements and extension of the organizations and provides valuable opportunity for promoting indicators of all organizations. In other words, educational organizations structure has relationship knowledge (Ghorbani, Tavasoli, Neghabi \& Nikookar, 2011). On the other hand, the most important of issues in one organization is high volume of information and knowledge that managers need to it.

Knowledge management includes strategic in the organizations (Demerest 1997, Rowley 2001, Soliman \& Spooner 2000, quoted from Zheng, 
yong \& mclean 2010). But, problem is that this knowledge and information is not available in times of need and there is no required capacity for remembering this high volume. Therefore, it seems that this issue should be examined in-depth and its problematic elements should be determined (Allameh, zamani \& Davari 2011).

Based on Probest, Rub \& Ramhart (2003), knowledge management can be identified by aim, knowledge - recognition, acquisition, development, sharing, knowledge - utilization, knowledge storage, and knowledge - assessment components. In present research, acquisition, sharing and keeping and knowledge - utilization components are considered. Based on it, knowledge acquisition refers to collect Knowledge through internal and external sources such as managers, experts, specialists and other external sources such as radio and TV. Sharing includes to the group and organization. Knowledge utilization indicates grant, decentralization and change in the decision of individuals based on group decisions and knowledge maintenance is related to Keep obtained knowledge (Ghorbani, TavasoliNeghabi \& Nikookar 2011).

Literature review of research shows that transferring and understanding high volume of information and knowledge in the organizations is affected by factors inside the organization and factors outside the organization (Zheng, Yong \& Mclean 2010).

One of the effective external factors on the knowledge management in the organizations is the structure and its dimensions. Organizational structure is the way or method by which organization activities are divided, organized and coordinated. Organizations have created structures to coordinate activities of factors doing task and to control acts of members (Erabi 1385). Three dimensions of complexity, formality and centralization are considered as the main Organizational dimensions in most researchers (Gholipour, 1380; willem \& Buelens 2009, Ghorbani, Tavasoli Neghabi \& Nikookar 2011).

Purpose of the complexity is the number of jobs subsystems that is done inside the organization or exist inside it. This dimension is divided into three categories-vertical differentiation, horizontal differentiation and differentiation spatial.
Formality refers to the rate or standard limit of organizational jobs, so that in the formal organization organizational relations are explained in written and accurately and according to the organizational chart for employees and if necessary, subsequent changes are formally anounced by manager. But, in the informal organization, organizational relationships are orally explained for employees and if necessary, they are naturally changed (Ghorbani, Tavasoli Neghabi \& Nikookar 2011), and centralization in the hierarchy of authorities is said to the level of authorities that has power of decision - making. When decisions are made in top organizational categories, the organization is called centralized. When decision -making is assigned to lower levels, organization is called decentralized (Trkman \& Desouza 2012). Now, a question that researcher tries to answer it in the end of this research is that have organizational structure dimensions positive effect on knowledge management in payame noor organization of Lorestan province?

\section{Materials and Method}

Present research is applied research. In this regard, descriptive - correlation analysis is used. Population of the research is all employees of Payame Noor university of Lorestan province that number of them is about 200 individuals. Also, stratified random sampling method is used for sampling. Since total number of employees is 200, sample volume Formula (Cochran formula) is as follow:

$$
\begin{gathered}
n=\frac{N Z_{1}^{2}-\propto y_{2} \cdot P q}{N d^{2}+Z^{2} \cdot P q} \\
n=\frac{200 \times(1 / 96)^{2} \cdot\left(\frac{1}{2} \times \frac{1}{2}\right)}{200 \times(0 / 5)^{2}+(1 / 96)^{2} \cdot\left(\frac{1}{2} \times \frac{1}{2}\right)}=n \\
=132
\end{gathered}
$$

With regard to above number, 135 questionnaires were distributed.

$\mathrm{N}$ : population size - total number of employees of Lorestan Payame Noor University

P: Success ratio

Z: standard variable of normal distribution

$\mathrm{n}$ : size of sample volume

q: failure ratio

$\propto$ : sampling estimation

d: sampling error 
For measuring research variables, closed - end questionnaire - response as a main tool - is used. For knowledge management, 30 item questionnaire and 14 item organizational structure dimensions are used. Both of them are questionnaire and their structure is as follow:

\begin{tabular}{|c|c|c|}
\hline questionnaire & Designer & Components \\
\hline $\begin{array}{c}\text { organizational structure } \\
\text { dimensions }\end{array}$ & Rabinz, 1989 & $\begin{array}{c}\text { Complexity, formality, } \\
\text { centralization }\end{array}$ \\
\hline knowledge management & Nonaka Takochi 2004 & $\begin{array}{c}\text { Acquisition, sharing, keeping, } \\
\text { utilization }\end{array}$ \\
\hline
\end{tabular}

For measuring research, 5 - point Likert scale is used as follow:

\begin{tabular}{|c|c|c|c|c|c|}
\hline organizational structure & Very high & high & almost & low & Very low \\
\hline value & 5 & 4 & 3 & 2 & 1 \\
\hline knowledge management & $\begin{array}{c}\text { Completely } \\
\text { disagreed }\end{array}$ & disagreed & No idea & agree & $\begin{array}{c}\text { Completely } \\
\text { agree }\end{array}$ \\
\hline value & 5 & 4 & 3 & 2 & 1 \\
\hline
\end{tabular}

\section{Reliability of measuring tool}

Reliability of a measuring tool mainly refers to accuracy of results from it (Sarmad et al, 1385, P. 166). In this research, Cronbach's alpha coefficient is used for validity of questionnaire.
For measuring reliability of questionnaires, first, about 30 questions are distributed between sample members that are calculated after collecting their reliability by cronbach's alpha and by of SPSS software.

\begin{tabular}{|c|c|c|}
\hline variable & question & Cronbach's alpha \\
\hline Knowledge acquisition & 10 & $0 / 714$ \\
\hline Knowledge sharing & 6 & $0 / 843$ \\
\hline Knowledge keeping & 9 & $0 / 753$ \\
\hline Knowledge utilization & 5 & $0 / 791$ \\
\hline Complexity & 5 & $0 / 836$ \\
\hline Formality & 4 & $0 / 865$ \\
\hline Centralization & 5 & $0 / 733$ \\
\hline Total questionnaire & 44 questions & $0 / 911$ \\
\hline
\end{tabular}

Result: Because all Cronbach's alpha is more than 0/7 , 50 reliability is confirmed.

Statistical analysis of observations

Data analysis is multistage procedure that during it, data that are provided from applying collection tools in the sample are coded, clustered and finally, processed to provide area of doing kinds of analysis and relationship between data in order to test.

In this research, structural Equation Method (SEM) is used in order to analyze observations. This method is one of the newest and most powerful methods of multivariate analysis that some has called it covariance structural analysis and causal modeling. Its main application is in multivariate issues way considering one independent variable with one dependent variable. Multivariate analysis is referred to series of analysis methods that their main feature is simultaneous multivariate independent analysis with multiple dependent variables. In other words, when you want to predict your dependent variable, for example delinquency with independent variables such as individual motivation, family relations, criminal record, social - economic status and so on, should address designing one causal model and its evaluation that you will be able to do using structural equations modeling.

SEM analysis can be done by two techniques:

1. Covariance structures analysis or linear structural relations (lisrel).

2. Partial least squares (PLS)

Structural equations technique is combination of two analyses: 
1. Confirmatory factor analysis (measuring model)

2. Path analysis - generalized regression analysis (structural model)

So, you measure some cases in this research directly (Section of measuring model) that is commonly items of questionnaire and obtain some of cases with combination of these items and compare them (section of model path analysis) to be able to draw your final model.

In other words, structural equations modeling is very general and powerful multivariate analysis techniques from Multivariate regression family and literally is "general linear model" that enables researcher to test set of regression equations at the same time.

Structural equation modeling is an holistic approach for testing hypothesis about observed variables relations and it is hidden that sometimes covariance structural analysis is called causal modeling and sometimes Lizrel. But, the dominat term in these days is the structural equation modeling or SEM (Hooman $1384,11)$

One of the basic concepts existing applied statistics in the medium level is the addition and multiplication transfers in the list of numbers, that is, if each of numbers of one list is multiplied in constant $\mathrm{K}$, average numbers is multiplied in the same $\mathrm{K}$ and so, standard deviation will be multiplied in the absolute value $\mathrm{K}$. The point is that if the set of numbers $\mathrm{X}$ is related to other set of numbers $\mathrm{Y}$ through equation of $y=4 x$, in this case, variance of $Y$ should be 16 times variance of $X$ and so, you can indirectly test this hypothesis that $\mathrm{Y}$ and $\mathrm{X}$ are related through equation $\mathrm{y}=4 \mathrm{x}$ through comparing variance of $\mathrm{X}$ and $\mathrm{Y}$.

This thought is generalized through number of linear equations from different ways to several variables related to each other. Although its rules become more complex and its calculations more difficult, but overall message remains constant. That is, examining variances and covariance of variables, you can test this hypothesis that "variables are related through set of linear relations".

Development of causal models of hidden variables indicates convergence of relatively independent research traditions in psychometrics, econometrics, biology and many already familiar methods that brings them into the broad framework. Discussion about hidden variables concepts against observed variables and error is issues of SEM.

\section{Results and discussion}

In this section, we address descriptive and inferential statistics. Table 1 presents description of respondents by gender.

Table 1 - 4: distribution of frequency and percent related to the selected employees by gender.

\begin{tabular}{|c|c|c|}
\hline Gender & Frequency & Percent of frequency \\
\hline Female & 44 & 33 \\
\hline Male & 88 & 67 \\
\hline Total & 132 & 100 \\
\hline
\end{tabular}

As seen, respondents were $67 \%$ women and $33 \%$ male.

Figure 1: percentage distribution related to the selected employees by gender.
In Table and Figure 2, respondents' description is presented by age.

Table 2: Frequency distribution and percent of frequency related to the selected employees by age

\begin{tabular}{|c|c|c|}
\hline Age & Frequency & Percent of frequency \\
\hline $20-30$ years & 12 & 9 \\
\hline $31-40$ years & 31 & 23 \\
\hline $41-50$ years & 69 & 52 \\
\hline Over 50 years & 20 & 16 \\
\hline Total & 132 & 100 \\
\hline
\end{tabular}

As seen, $9 \%$ of respondents have age between 21 to 30 years, $23 \%$ between 31 to 40 years,
$52 \%$ between 41 to 50 years and remaining $16 \%$ have more than 50 years. 
Diagram 2: Frequency distribution related to the selected employees by age.
In Table and Graph 3, respondents' description is shown by education.

Table 3: Frequency distribution and percent of frequency related to the selected employees by education.

\begin{tabular}{|c|c|c|}
\hline Education & Frequency & Frequency Percent \\
\hline Diploma or less & 3 & 2 \\
\hline AA & 14 & 10 \\
\hline BS & 85 & 64 \\
\hline MA or higher & 30 & 24 \\
\hline Total & 132 & 100 \\
\hline
\end{tabular}

Resource $=$ research calculations

As we seen, $16 \%$ of respondents have diploma or less, $20 / 5 \%$ AA, $46 \%$ BS and $17 / 5 \%$ MA and higher.

Graph 3: Frequency distribution related to the selected employees by education
After examining descriptive statistics, inferential statistics are studied. First of all, data normalization is examined using Kolmogorov - Smirnov test.

Results of this test are given in Table 4.

Table 4: Results of Kolmogorov - Smirnov test

\begin{tabular}{|c|c|c|}
\hline Variable & Significant level & Condition \\
\hline Knowledge management & $0 / 302$ & Distribution is normal \\
\hline Complexity & $0 / 67$ & Distribution is normal \\
\hline Formality & $0 / 183$ & Distribution is normal \\
\hline Centralization & $0 / 307$ & Distribution is normal \\
\hline
\end{tabular}

Given that significant level for all variables is more than $5 \%$ level of the research error, then data distribution is normal. After examining normality of variables, fitness of model is studied. Results from fitness tests of the model are presented in Table 5.

Table 5: Results from fitness tests

\begin{tabular}{|c|c|c|}
\hline Index & Calculated Value & Description \\
\hline RMR & $0 / 007$ & Because it is close to Zero, then it approves fitness. \\
\hline GFI & $0 / 98$ & $\begin{array}{c}\text { Because is bigger than } 0 / 9 \text { and smaller than } 1 \text {, than it approves the } \\
\text { fitness. }\end{array}$ \\
\hline AGFI & $0 / 91$ & $\begin{array}{c}\text { Because is bigger than } 0 / 9 \text { and smaller than } 1 \text {, than it approves the } \\
\text { fitness. }\end{array}$ \\
\hline RMSEA & $0 / 06$ & Because it is smaller than $0 / 1$, than it approves the fitness. \\
\hline NFI & $0 / 92$ & Because it is bigger than $0 / 9$, than it approves the fitness. \\
\hline CFI & $0 / 95$ & Because it is bigger than $0 / 9$, than it approves the fitness. \\
\hline
\end{tabular}

Since according to the results of calculations, all criteria approve the fitness, so overall fitness of the model is approved relative to the presented questions and we can estimate the model without worry about being fake of regression.
Standard coefficients of SEM are given in Graph

4. Graph 4: Standard coefficients of SEM

In table 6 , explanations relative to above model are presented.

Table 6: latent variables, name and related variables

\begin{tabular}{|c|c|}
\hline Latent Variables & Name \\
\hline $\mathrm{X}$ & Knowledge management \\
\hline $\mathrm{Y}_{1}$ & Complexity \\
\hline $\mathrm{Y}_{2}$ & Formality \\
\hline $\mathrm{Y}_{3}$ & Centralization \\
\hline
\end{tabular}


Results of T - test are shown in Graph 5.

Graph 5: Results of $\mathrm{T}$ - test

4.1. Statistical analysis of Hypothesis 1 of the research

Complexity dimension affects knowledge management (acquisitions, sharing, utilization and knowledge maintenance).
Examination of relationship among variables of "complexity" and "knowledge management" is discussed in this section. For this purpose, we examine relationship among these two latent endogenous variables.

Table 7: statistical value of $\mathbf{T}$ - test and coefficient of $\boldsymbol{\gamma}$ for hypothesis 1

\begin{tabular}{|c|c|c|}
\hline statistical value & Standard error & $\gamma$ \\
\hline of T - test & error & \\
\hline $9 / 03$ & $0 / 043$ & $0 / 45$ \\
\hline
\end{tabular}

Result: Because statistical value of $\mathrm{T}-$ test $(9 / 03)$ is bigger than $t$ value (1/96), so the null hypothesis is approved.

Rejection of Ho in significant level of $0 / 5$ ( $t<$ 1/96) indicates that there is significant relationship among "complexity" and "knowledge management" variables.

In simple terms, in significant level of $0 / 5$ "complexity" dimension affects "knowledge management". Corresponding $\gamma$ coefficient indicates positive and direct relationship among two examined variables. In other words, for one percent change in complexity dimension knowledge management will change $45 \%$.

4.2. Statistical analysis of hypothesis 1 of the research

"Formality dimension" affects knowledge management (acquisitions, sharing, utilization and knowledge maintenance).

Relationship among "formality dimension" and "knowledge management" is discussed in this section. For this purpose, we examine the relationship among these two latent endogenous variables.

Table 8: statistical value of $\mathbf{T}$ - test and $\gamma$ coefficient for second hypothesis

\begin{tabular}{|c|c|c|}
\hline statistical value & Standard error & $\gamma$ \\
\hline of T - test & & $0 / 16$ \\
\hline $3 / 54$ & $0 / 054$ & ch \\
\hline
\end{tabular}

other words, for one percent of change in the

Result: Because statistical value of test (3/54) is bigger than $t$ value (1/96), so the null hypothesis is rejected and researcher hypothesis is approved. Rejection of Ho in the significant level of $\% 5$ (t $<1 / 096$ ) indicates that there is significant relationship among "formality dimensions" variables and "knowledge management", in simple terms, in the significant level of $0 / 5$, effect of formality dimensions is approved on knowledge management. Corresponding $\gamma$ coefficient indicates positive and direct relationship among two examined variables. In formality dimensions, knowledge management will change 16 percent.

4.3. Statistical analysis of hypothesis 3 of the research

"Centralization dimension" affects knowledge management (acquisitions, sharing, utilization, knowledge maintenance).Relationship among "centralization dimension" variables and "knowledge management is discussed in this section. For this purpose, examination of relationship among two endogenous latent variables is studied.

Table 9: Statistical value of T-test and $\gamma$ coefficient for third hypothesis

\begin{tabular}{|c|c|c|}
\hline statistical value & Standard error & $\gamma$ \\
\hline of T - test & & $0 / 18$ \\
\hline $4 / 23$ & $0 / 043$ & 043 \\
\hline
\end{tabular}

Result: Because statistical value of T-test (4/23) is bigger than $\mathrm{t}$ value (1/96), so the null hypothesis is rejected and researcher hypothesis is approved.
Rejection of Ho in the significant level of $\% 5$ (t $<1 / 096$ ) indicates that there is significant relationship among "centralization dimension" and "knowledge management", in simple terms, 
in the significant level of $0 / 5$, "centralization dimension" affects "knowledge management". Corresponding $\gamma$ coefficient indicates positive and direct relationship among two examined variables. In other words, for one percent of change in centralization dimension, knowledge management will changed $18 \%$.

Table 9: Statistical equation of model regression

\begin{tabular}{|c|c|c|c|}
\hline Variables & Complexity & Formality & centralization \\
\hline Symbol & $\mathrm{Y}_{1}$ & $\mathrm{Y}_{2}$ & $\mathrm{Y}_{3}$ \\
\hline knowledge management & $0 / 24$ & $0 / 21$ & $/ 58$ \\
\hline
\end{tabular}

Overall equation of the research model is given in equation 1 :

$\mathrm{X}=0 / 58 \mathrm{y} 1+0.21 \mathrm{y} 2+0.24 \mathrm{y} 3$

In this equation, regression coefficient constant has been removed suggesting that equation is standard. Above equation coefficients indicate that if two components are kept constant, third component has effect on the knowledge management. For example, complexity coefficient in this equation is $0 / 58$. So, if the formality dimension and centralization are kept constant, structure complexity affects $58 \%$ on the knowledge management.

Table 10: matrix of structural coefficients of independent variables ( $\mathrm{Fi}$ - Matrix)

\begin{tabular}{|c|c|c|c|}
\hline & $Y_{1}$ & $Y_{2}$ & $Y_{3}$ \\
\hline$Y_{1}$ & $0 / 567$ & & \\
\hline$Y_{2}$ & $0 / 428$ & $0 / 182$ & $0 / 023$ \\
\hline$Y_{3}$ & $0 / 044$ & $0 / 090$ & \\
\hline
\end{tabular}

Table 11: Matrix correlation between independent variables of the research

\begin{tabular}{|c|c|c|c|}
\hline & $\mathrm{Y}_{1}$ & $\mathrm{Y}_{2}$ & $\mathrm{Y}_{3}$ \\
\hline $\mathrm{Y}_{1}$ & 1 & & \\
\hline $\mathrm{Y}_{2}$ & $0 / 53$ & 1 & \\
\hline $\mathrm{T}-$ value & $9 / 15$ & & 1 \\
\hline $\mathrm{Y}_{3}$ value & $0 / 43$ & $0 / 26$ & \\
\hline
\end{tabular}

As we seen, all significant levels ( $\mathrm{t}$ - value) for correlation of independent variables are more than $1 / 96$, then it can be said that all these correlations are significant relationship between organizational structure dimensions.

\section{Conclusion}

Most decision - makers are not interested in the details of the research process. Their emphasis is on final information (and no data) and how to adapt to their information needs for different decision - makings. However, it is important that decision - maker knows necessary details about research project to judge about the research limitations and resources of errors existing in the findings.

Results of the research show that there is direct and significant relationship between complexity dimension and knowledge management (acquisition sharing, utilization and knowledge maintenance) in error level of $5 \%$. This means that when complexity dimension is more, the effect of knowledge management (acquisition, sharing, utilization and knowledge maintenance) in the organization will be more. In other words, for one percent change in the complexity dimension, the effect of knowledge management (acquisition, sharing, utilization and knowledge maintenance) become $45 \%$ more. Results of this case are identical to the results from the research of Ghorbani et al (2011) and Abotorabi (1386). In addition, results show that there is direct and significant relationship between formality dimension and knowledge management (acquisition, sharing, utilization and knowledge maintenance) in the error level of 5\% this means that when the formality dimension be mere, the effect of knowledge management (acquisition, sharing, utilization and knowledge maintenance) in the organization will be more. In other words, for one percent change in the formality dimension, the effect of knowledge management (acquisition, sharing, utilization and knowledge maintenance) will become $16 \%$ more. Results of 
this case are identical to the results from the research of Ghorbani et al (2011) and Abotorabi (1386).

About third hypothesis, it can be said that results show that there is direct and significant relationship between centralization dimension and knowledge management (acquisition, sharing, utilization, knowledge maintenance) in the error level of $5 \%$.

This means that when the centralization dimension is more, the effect of knowledge management (acquisition, sharing, utilization, knowledge maintenance) in the organization will be more.

In other words, for one percent change in the centralization dimension, the effect of the knowledge management dimensions (acquisition, sharing, utilization, knowledge maintenance) will be $18 \%$ more. Results of this hypothesis are identical to the research results from Ghorbani et al (2011) and Abotorabi (1386).

\section{Resources}

Azar, Adel and Zali, Mohammad Reza "In search of techniques to Determine validity in the management Researches", Quarterly of management culture, 4th year, No 14, Fall and winter 1385, PP 5-26.

Abili, khodayar and moafaghi, Hassan." Management of Scientists Performance (article), site of Industrial Management Organization 1388

3. R. K. Jin, H, C, Trayandys "Management on Integral Management", Translation and Publication of Educational and Research Institution of Defense Industry, 2th Edition, Tehran: 1381.

4. Doaei, Habibolah; Human Resources Management; 5th Edition, Bayan Hedayat Publication, mashable, 1381.

5. Khaki, GholamReza, "Research Method with Approach to Dissertation", Baztab Publications, Tehran, 1378.

Peter Drucker; Future Management, translated by Abdoreza Rezaei Nezhad, "khadamat Farhangi Rasa" Institution, First Edition, 1373, P 347 - 352.

Adyzes, Issac 1373. Organization Period of Life (First Edition), translated by Mohammad sirous, Tehran; Eshraghiyeh Publication.
Daft, Richard 1374. Theoried of the Organization and Structure Design of Tehran: Sherratt Edition and Business Publication.

Sarmad, Zohreh, Bazargan, Abbas and Hejazi, Elaheh, Research Methods in Behavioral Sciences, Agah Publications, Tehran, 1385.

Sarraf, AliReza; Standardization Process of Service about Clients with Approach of Service Quality in the Public Sector, Quarterly of " Tahavol Edari ", No 45, Fall 1385, PP $71-90$.

Robbins, Stephen 1369. Organizational Behavior Management (Group Behavior), Second Volume, (first edition), translated by Ali Parsaeian and Seyed Mohammad Erabi, Tehran, Business Studies and Researches Institution.

Fitz Simmons, James. A and Fits Simmons, Mona J, "Service Management: Strategy, Operation and Information Technology; translated by Seyed Mohammad Erabi and Davood Izadi, "Cultural Researchs office" Institution, Tehran, Volum first, 1382.

Adyzes Isaac. Organization Priod of life, First Edition, translated by Kaveh Mahammad Cirrus, Tehran, Eshraghiyeh Publication, 1373.

Nikoo Eghbal - Ali Akbar, choice of organization and Management Theories, Organization of Study and Collecting books of Human Sciences of Universities (Samt), first Eolition, Summer, 1378 $-\mathrm{P} 72$.

Kuklan - Hooshang, Organizational Behavior Human Relations, Tehran, Administrative Sciences and Business Management University Publications of Tehran University, First Edition, 1385, P 143

Farhang, Ali Akbar, Philosophical - Social. Attitude on Job and its Problems, Management knowledge, No 12. Administrative Sciences and Business Management University, Tehran university, spring 1370, P 24

Alvani, Seyed Mahdi and Danaei Fard, Hassan, 1380. Public Management and Public Confidence, Management Knowledge, Publication of Management Faculty of Tehran University, $14^{\text {th }}$ year, No 55

Behboodian, Javad, Nonparametric Statistics, Shiraz, Publication Center of Shiraz University, 3th edition, 1378.

Toureh, Naser 1384. Understanding Organizational Citizenship Behavior Components and their 


\section{Examining Effect of Organizational Structure}

Relationship with Organizational Performance, MA Thesis, Tehran University, Qom campus, 62.

Danaei Fard, Hassan 1387. Challenges of Public Management in Iran, Tehran Organization of Study and Collecting books of Human Sciences Universities (samt), Research and Development center of Human Sciences.

Momeni, Mansour, Fa'al Ghayoomi, Ali. 1389, Statistical Analysis using SPSS. 3th edition, "ketabe No" Publication, Tehran.

Pakseresht, Hassan 1382. Knowledge Management, "Daneshkar" Publication.

Cast, $\mathrm{k}$ and T.S.A Fasih 1983. Knowledge Management from the view of Business Strategy, Information Sciences. $18(3,4)$
Kalantar, M,J,S 1382. Knowledge Management in Organization. Tadbir 142.

Momeni, M,V. Tarzi 1985. MA Project with Title of Collecting Requirements of Implanting Knowledge Management in Process of Product Development in Automobile Industry. Information Technology Management Period, Industrial Management Organization.

Knowledge Management from the view of a Business Strategy. Written by Carl Karest, translated by Sedigheh Ahmadi Fasih, (Master of National Library of Islamic Republic of Iran).

Mohammad Ali Nadi 1386. The Role of Knowledge Management and Pervasive Quality Management in learned Organization, Ph.D. Thesis of Education Management, Islamic Azad university, Branch of Science and Research. 